\title{
Modulation of Monocyte-Endothelial Cell Interactions by Platelet Microparticles
}

\author{
Orla P. Barry, ${ }^{*}$ Domenico Praticò, ${ }^{*}$ Rashmin C. Savani, ${ }^{\ddagger}$ and Garret A. FitzGerald ${ }^{\star}$ \\ $*$ Center for Experimental Therapeutics and ${ }^{\ddagger}$ Division of Neonatology, Department of Pediatrics, University of Pennsylvania School of \\ Medicine, Philadelphia, Pennsylvania 19104-6100
}

\begin{abstract}
Platelets, activated by various agonists, produce microparticles (MP) from the plasma membrane, which are released into the extracellular space. Although the mechanism of MP formation has been clarified, their biological importance remains ill defined. We have recently shown that plateletderived MP influence platelet and endothelial cell function. In this study, we have further examined the mechanism of cellular activation by platelet MP. To address the possibility that they may influence monocyte-endothelial interactions, we used an in vitro assay to examine their effects on the adhesion of monocytes to human umbilical vein endothelial cells (HUVEC). Platelet MP increased the adhesion of monocytes to HUVEC in a time- and dose-dependent manner. Maximal adhesion of monocytes to resting HUVEC was observed after $24 \mathrm{~h}$ of stimulation with MP. Similar kinetics were observed with U-937 (human promonocytic leukemia) cells, used as a model for the blood-borne monocyte. Maximal adhesion of resting monocytes to MP-stimulated HUVEC was observed after $5 \mathrm{~h}$ of stimulation with MP. The $\mathrm{EC}_{50} \mathrm{~s}$ for MP-induced increases in HUVEC, monocyte, and $\mathrm{U}-\mathbf{9 3 7}$ cell adhesion is $\mathbf{8 . 7 4}, \mathbf{4 3 . 4 1}$, and $10.83 \mu \mathrm{g} / \mathrm{ml}$ of MP protein, respectively. The induction of monocyte-endothelial adhesion was mimicked by arachidonic acid isolated from MP. The observed increased cellular adhesiveness correlated with MP-induced upregulation of cell adhesion molecules. MP-stimulated HUVEC increased intracellular cell adhesion molecule-1 (ICAM-1) but not vascular cell adhesion molecule-1 (VCAM-1), P-, or E-selectin expression. Monocyte and U-937 lymphocyte function-associated antigen-1 (CD11a/CD18) and macrophage antigen-1 (CD11b/ CD18, $\alpha_{m} / \beta_{2}$ ) were both upregulated upon MP stimulation, but an increase in p150,95 (CD11c/CD18), very late antigen-1, or ICAM-1 expression was not observed. The functional importance of these changes was demonstrated with blocking antibodies. MP also induced the chemotaxis of U-937 cells in a dose-dependent manner with an $\mathrm{EC}_{50}$ of $4.40 \mu \mathrm{g} / \mathrm{ml}$ of MP protein. Similarly, arachidonic acid isolated from MP mimicked the chemotactic response. A role
\end{abstract}

Address correspondence to Garret A. FitzGerald, Center for Experimental Therapeutics, 905 Stellar-Chance Laboratories, University of Pennsylvania School of Medicine, Philadelphia, PA 19104-6100. Phone: 215-898-1185; FAX: 215-573-9135; E-mail: garret@spirit.gcrc. upenn.edu

Received for publication 19 December 1997 and accepted in revised form 21 April 1998.

J. Clin. Invest.

(C) The American Society for Clinical Investigation, Inc. 0021-9738/98/07/0136/09 \$2.00

Volume 102, Number 1, July 1998, 136-144

http://www.jci.org for PKC was implicated in both adhesion and chemotaxis. GF 109203X, a specific inhibitor of PKC, significantly reduced monocyte-endothelial adhesion, as well as U-937 chemotaxis. The demonstration that platelet MP may modulate important aspects of endothelial and monocyte function provides a novel mechanism by which platelets may interact with such cells in human atherosclerosis and inflammation. (J. Clin. Invest. 1998. 102:136-144.) Key words: arachidonic acid $\bullet$ ICAM-1 $\cdot$ CD11a $\cdot$ CD11b $\bullet$ adhesion

\section{Introduction}

Cellular activation by physiological agonists may result in membrane vesiculation, followed by shedding of blebs or microparticles $\left(\mathrm{MP}^{1} ; 1-3\right)$. Such MP may contain proteins and lipids that subserve mediator functions in the context of the intact cell $(4,5)$. For example, platelet-derived MP contain pro- and anticoagulant proteins (6). Both platelet and endothelial cell MP also contain bioactive lipids $(7,8)$; indeed, we have recently shown that platelet MP arachidonic acid (AA) can both activate adjacent platelets by donation of substrate for thromboxane $\mathrm{A}_{2}$ formation and induce endothelial prostacyclin formation via upregulation of cyclooxygenase-2 (9). The possibility that platelet-derived MP might modulate the likelihood of thrombosis led us to address the possibility that they might also influence other aspects of cellular interactions with the vessel wall.

The precise role of platelet activation in vascular proliferative disorders is unclear $(10,11)$. Intense platelet activation accompanies the vascular injury attendant to coronary angioplasty. However, despite the release of growth factors by activated platelets in vitro (12), it is unclear whether they play an important causative role in the proliferative process that results in coronary restenosis (13). For example, clinical trials of aspirin and other platelet inhibitors (14-16) have failed to influence this process. However, an animal model of acute vascular injury and platelet activation is complicated by a chronic vascular proliferative lesion, which is ameliorated by more potent inhibitors of platelet glycoprotein IIb/IIIa (GpIIb/IIIa; 17). There has also been some suggestion of an effect of GpIIb/IIIa inhibitors on restenosis after coronary angioplasty in humans (18). This possibility is presently being addressed more formally.

The importance of platelet activation in atherogenesis is, if anything, even more speculative. Whereas the release of platelet-derived growth factor from activated platelets was proposed to play a central role in the original "vascular injury" hypothesis of atherogenesis $(10,19)$, the lack of experimental

1. Abbreviations used in this paper: AA, arachidonic acid; HUVEC, human umbilical vein endothelial cells; ICAM-1, intracellular adhesion molecule-1; MP, microparticles; PKC, protein kinase C; PRP, platelet-rich plasma. 
evidence in support of this concept prompted a revised view of the importance of platelet activation (20). More recently, attention has centered on the monocyte-macrophage. Currently, it is thought that circulating monocytes are recruited to adhere to dysfunctional, but intact, endothelial cells at an early stage in the process of atherogenesis. After their adherence, monocytes migrate across the endothelium and transform to macrophages. These cells ingest oxidized lipoprotein, ultimately forming foam cells, a characteristic feature of atherosclerotic plaques $(21,22)$. Although platelets may not contribute directly to plaque formation, platelet activation is a feature of atherosclerotic vascular disease in humans. This is true in the setting of acute plaque rupture (23), where platelet activation is central to the likelihood of acute vascular occlusion, but also in patients with more stable, but severe disease (24). Given that platelet MP have been reported to circulate in human syndromes of platelet activation and inflammation $(25,26)$ and that flow dynamics predict their accumulation at sites of developing atherosclerosis (27), we speculated that they might represent a mechanism by which platelets modulate monocyteendothelial interactions.

We now report that platelet-derived MP increase the adhesive interactions between endothelial cells and both monocytes and monocytoid cells. MP-induced adhesiveness occurs via upregulation of monocyte and U-937 CD11a and CD11b and endothelial cell intracellular adhesion molecule-1 (ICAM-1). Furthermore, platelet MP increase U-937 cell chemotaxis and induce upregulation of CD14, a marker of their differentiation (28). Interestingly, these effects, similar to MP-induced platelet activation and endothelial cell cyclooxygenase- 2 expression, are attributable to MP AA acting via a protein kinase $\mathrm{C}$ (PKC) sensitive pathway.

These data suggest that concentrated delivery of bioactive lipids in MP may not only influence thrombosis, but also modulate multicellular interactions of relevance to the early stages of atherogenesis.

\section{Methods}

Reagents. Indomethacin, cycloheximide, actinomycin D, and Rose Bengal were purchased from Sigma Chemical Co. (St. Louis, MO). GF 109203X (bisindoylmaleimide) and H-89( $N$-[2-(p-bromocinnamylamino) ethyl]-5-isoquinolinesulfinamide) were purchased from Calbiochem (La Jolla, CA). A number of antibodies were generously provided for these studies. These included a mAb directed against the common $\beta$-chain (CD18, IB4, murine, purified IgG) from D. Altieri (Yale University, New Haven, CT), and anti-ICAM-1 (RR1/1.1.1) from R. Rothlein (Boehringer Ingelheim, Ridgefield, CT), both of which had a blocking function. L. Languino (Yale University, New Haven, CT) kindly donated TS2/16 directed against $\beta_{1}$ integrins, which was used for FACScan ${ }^{\circledR}$ analysis. Anti-CD11a, -CD11b, and $-\mathrm{CD} 11 \mathrm{c}$ were purchased from Immunotech (Westbrook, ME). Anti-CD14, -CD62E, -CD62P, -CD54, and -CD106 were purchased from PharMingen Corp. (San Diego, CA). All of these antibodies were used for FACScan ${ }^{\circledR}$ analysis. Anti-CD11a, -CD11b, -CD14, and $-\beta_{3}$, all with a blocking function, were purchased from Becton Dickinson (Franklin Lakes, NJ). FITC-conjugated $\mathrm{F}\left(\mathrm{ab}^{\prime}\right) 2$ fragments of goat anti-mouse and goat anti-rat IgG were purchased from Cappel Laboratories (West Chester, PA). U-937 cells were purchased from the American Type Culture Collection (Rockville, MD).

Isolation of platelets, preparation of platelet $M P$, and their identification. Platelets were harvested as described previously (29). The volunteers had not taken any medication for at least $14 \mathrm{~d}$. Briefly, blood was collected into a plastic syringe containing $3.8 \%$ buffered sodium citrate as anticoagulant (ratio 1:9). Platelet-rich plasma (PRP) was prepared by centrifugation at $130 \mathrm{~g}$ for $15 \mathrm{~min}$, and platelet-poor plasma by centrifugation of PRP at $900 \mathrm{~g}$. Washed platelets were isolated from PRP after centrifugation and resuspended in calcium- and magnesium free Hepes buffer ( $\mathrm{pH}$ 7.4). The platelet number was always adjusted to $3 \times 10^{8} / \mathrm{ml}$. Platelet aggregation was studied at $37^{\circ} \mathrm{C}$ using washed platelets in a PAP-4 model aggregometer (BIO-DATA Corporation, Hatboro, PA) in siliconized cuvettes with continuous stirring.

Platelet MP were isolated after platelet aggregation and characterized using a flow cytometer (Coulter Corporation, Hialeah, FL) (9). Each platelet MP preparation was assayed for endotoxin contamination using the Limulus amebocyte lysate assay: final endotoxin contamination was always $<0.02 \mathrm{U} / \mathrm{mg}$ protein. Experiments were performed with platelet MP that were preincubated with polymixin B $(50 \mu \mathrm{g} / \mathrm{ml})$ for $1 \mathrm{~h}$ to further exclude any possible contamination.

Isolation of arachidonic acid from MP. AA isolation was performed as previously described (9). Briefly, lipids were extracted according to a modified version of the method of Bligh and Dyer (30) and separated as previously described (9). The free fatty acid fraction was purified by $\mathrm{NH}_{2}$ column chromatography (International Sorbent Technology, Glamorgan, UK) followed by TLC. The band with the same $R_{f}$ as standard arachidonic acid was extracted from the TLC plate and purified by reverse phase high performance liquid chromatography. Identification of AA was confirmed by negative ion chemical ionization mass spectrometry, as previously described (9).

Cell culture. Human umbilical vein endothelial cells (HUVEC) were prepared according to the method of Jaffe et al. (31). They were maintained in medium 199 (Boehringer Mannheim, Indianapolis, IN), containing $10 \%$ heat-inactivated fetal calf serum, $2 \mathrm{mM}$ L-glutamine, $100 \mu \mathrm{g} / \mathrm{ml}$ streptomycin, and $100 \mathrm{U}$ of penicillin, $10 \mu \mathrm{g} /$ $\mathrm{ml}$ heparin, and $50 \mu \mathrm{g} / \mathrm{ml}$ endothelial growth supplement. HUVEC were selected for experimental use at passage level 1. Passage cells were subcultured into 96 -well plates $\left(10^{3}\right.$ cells/well $)$ and were allowed to grow for $48 \mathrm{~h}$ to reach subconfluence before stimulation. The subconfluent state, however, is not critical.

U-937 cells, were cultured in RPMI 1640 medium supplemented with $10 \%$ heat-inactivated fetal calf serum, $2 \mathrm{mM}$ L-glutamine, 100 $\mu \mathrm{g} / \mathrm{ml}$ streptomycin, and $100 \mathrm{U}$ of penicillin. U-937 cells were maintained in $\log$ phase and cell number was maintained at $10^{6} \mathrm{cells} / \mathrm{ml}$.

Monocytes were obtained from fresh peripheral blood of healthy volunteers, who did not take any medication during the previous $2 \mathrm{wk}$. Blood was subject to Ficoll-Hypaque (Pharmacia Fine Chemicals, NJ) density gradient centrifugation as described by Boyum (32). The mononuclear cell layer was recovered and washed with Hanks' balanced salt solution. The cells were resuspended in RPMI 1640 medium containing $10 \%$ heat-inactivated fetal calf serum and EDTA for $15 \mathrm{~min}$ at $37^{\circ} \mathrm{C}$ to remove platelets specifically adherent to the monocytes. They were washed twice in Hanks' balanced salt solution and resuspended at $10^{6} / \mathrm{ml}$ in RPMI 1640 medium supplemented with $2 \mathrm{mM}$ L-glutamine, $100 \mu \mathrm{g} / \mathrm{ml}$ streptomycin, and $100 \mathrm{U}$ of penicillin. More than $95 \%$ of the cells were estimated to be viable, based on trypan blue dye exclusion. The cells were plated in 6-well multiwell plates and maintained at $37^{\circ} \mathrm{C}$. The nonadherent cells were removed by washing the plates twice with Dulbecco's phosphate-buffered saline after $2 \mathrm{~h}$ of incubation, and the adherent cells were maintained in RPMI 1640 medium supplemented with $5 \%$ heat-inactivated fetal calf serum, $2 \mathrm{mM} \mathrm{L}$-glutamine, $100 \mu \mathrm{g} / \mathrm{ml}$ streptomycin, and $100 \mathrm{U}$ of penicillin. The resultant harvested adherent cells routinely contained $>93 \%$ monocytes, as determined by morphology and staining for nonspecific esterase (33).

Cell stimulation and adherence. To investigate the effects of MP on HUVEC, monocyte, or U-937 adhesion, cells were stimulated with increasing concentrations of platelet MP protein or MP AA for $5 \mathrm{~h}$. Indomethacin $(20 \mu \mathrm{M})$ was always present in the medium to prevent AA metabolite formation. After $5 \mathrm{~h}$ of stimulation, medium was removed from the HUVEC, the plate washed three times with PBS/ EDTA to remove any adherent MP or excess AA, and examined mi- 
croscopically to ensure complete removal of MP. Blood monocytes and U-937 cells were pelleted after stimulation by centrifugation at $1,200 \mathrm{rpm}$ for $5 \mathrm{~min}$, and later washed three times with PBS/EDTA. HUVEC, monocytes, or U-937 cells were incubated for 1, 5, or $24 \mathrm{~h}$ with MP to characterize the time dependence of cell adhesion. Cells were washed as described in the experiments to explore the dose dependence of MP-induced effects. Monocytes or U-937 cells $\left(10^{5}\right)$ were added to subconfluent HUVEC and allowed to adhere at $37^{\circ} \mathrm{C}$ for $1 \mathrm{~h}$ in a $5 \% \mathrm{CO}_{2} / 95 \%$ air incubator. Microscopic examination confirmed that cells were attached individually and not by self-aggregation. GF 109203X $(5 \mu \mathrm{M}), \mathrm{H} 89$ dihydrochloride $(10 \mu \mathrm{M})$, and cycloheximide (5 $\mu \mathrm{g} / \mathrm{ml}$ ) were preincubated with either HUVEC, U-937 cells, or monocytes for $45 \mathrm{~min}$ before MP and Actinomycin D $(12 \mu \mathrm{M})$ were coincubated with MP.

Measurement of adherent cells. A sensitive ELISA method based on the cellular uptake of Rose-Bengal stain was used to measure the increase in adherence interactions after MP stimulation (34). Briefly, bound monocytes or U-937 cells on HUVEC were treated with $0.25 \%$ Rose-Bengal in PBS (100 $\mu \mathrm{l} /$ well $)$ for $10 \mathrm{~min}$ at room temperature after adhesion. The stain was removed by aspiration and wells were washed with PBS and $10 \%$ heat-inactivated fetal calf serum. Cells were treated with a solution of ethanol and PBS for $30 \mathrm{~min}$ to release the stain. Optical density at $570 \mathrm{~nm}$ for each well was determined by using an ELISA reader (Dynatech Microplate MR600; Dynatech, Alexandria, VA).

Effect of blocking antibodies. To examine the effects of blocking antibodies against surface antigens, U-937 cells were pretreated for $1 \mathrm{~h}$ at $4^{\circ} \mathrm{C}$ with anti-CD18, $(10 \mu \mathrm{g} / \mathrm{ml})$, anti-CD14, anti-CD11a, and antiCD11b $(5 \mu \mathrm{g} / \mathrm{ml})$. HUVEC were treated with anti-ICAM- $1(20 \mu \mathrm{g} / \mathrm{ml})$. To address the possibility that $\alpha_{\text {II }} \beta_{3}$ on MP may act as a bridge between ICAM-1 and/or $\alpha_{\mathrm{m}} \beta_{2}$ on endothelial cells and leukocytes, respectively, both U-937 cells and/or HUVEC were treated with anti- $\beta_{3}$ $(10 \mu \mathrm{g} / \mathrm{ml})$. Cells were incubated with control $\mathrm{IgG}$ antibodies or an equivalent volume of PBS in each experiment. Antibodies were not removed during incubation of U-937 with HUVEC and did not cause aggregation of cells under the conditions tested.

Test of antibody saturation. Samples were analyzed by flow cytometry to ensure that functional antibody remained after conclusion of U-937 adhesion to HUVEC. HUVEC or U-937 cells were incubated with experimental supernatants or fresh media containing the appropriate antibody for $1 \mathrm{~h}$ at $4^{\circ} \mathrm{C}$. Cells incubated with supernatants without $\mathrm{Ab}$ from control experiments, or with fresh medium without added $\mathrm{Ab}$ were used as negative controls. Samples were labeled with either FITC-goat anti-mouse or anti-rat IgG and analyzed on a EPICS XL flow cytometer (Coulter Corporation, Hialeah, FL).

Flow cytometry. Cell surface antigen expresssion on HUVEC, U-937, or monocytes were examined by flow cytometry. Briefly, subconfluent HUVEC monolayers or U-937 cells and monocytes $\left(10^{5}\right)$ either treated or not with MP or MP AA, were incubated with $100 \mu$ of the appropriate amount of the primary $\mathrm{mAb}$ for $1 \mathrm{~h}$ at $4^{\circ} \mathrm{C}$ with agitation. Indomethacin $(20 \mu \mathrm{M})$ was added to the medium to prevent AA metabolite formation. The antibodies used (all $\mathrm{IgG}$ isotope) were antiCD11a, -CD11b, -CD11c, -CD14, -CD62E, -CD62P, -CD54, -CD106, and TS2/16 at $5 \mu \mathrm{g} / \mathrm{ml}$. FITC-conjugated $\mathrm{F}\left(\mathrm{ab}^{\prime}\right)_{2}$ fragments of goat anti-mouse or goat anti-rat IgG were used as secondary Abs. Cells incubated with FITC-conjugated $\mathrm{F}\left(\mathrm{ab}^{\prime}\right)_{2}$ fragments only were used as negative controls. The secondary FITC-conjugated $\mathrm{Ab}$ was added to each sample $(10 \mu \mathrm{g} / \mathrm{ml})$ for thirty $\min$ at $4^{\circ} \mathrm{C}$ with agitation. Samples were analyzed using an EPICS XL flow cytometer.

Chemotaxis assay. We used a 96-well chemotaxis chamber to investigate MP or MP AA-induced chemotaxis of U-937 cells (35). The chamber consists of an upper and lower compartment separated by a $5-\mu \mathrm{m}$ framed filter. The lower section was filled with media alone, media containing MP, or media containing MP AA. The upper chamber was filled with $200 \mu$ l of U-937 cell suspension $\left(2 \times 10^{5}\right)$. Cells were variously incubated with GF $109203 X(5 \mu \mathrm{M})$, H89 dihydrochloride $(10 \mu \mathrm{M})$ for $45 \mathrm{~min}$, or $100 \mathrm{nM}$ PMA for $48 \mathrm{~h}$, before their addition to the upper chamber.
Assays were carried out at $37^{\circ} \mathrm{C}$ in $5 \% \mathrm{CO}_{2} / 95 \%$ air for $24 \mathrm{~h}$. Upon completion of incubation, the medium in the upper chamber was removed and replaced with $200 \mu \mathrm{l}$ PBS and $20 \mu \mathrm{M}$ EDTA, and incubated at $4^{\circ} \mathrm{C}$ for $30 \mathrm{~min}$. Cells that did not undergo chemotaxis were removed from the upper surface of the polycarbonate filter, whereas cells that had migrated into the lower chamber were collected by centrifugation at $500 \mathrm{~g}$ for $10 \mathrm{~min}$.

MTT assay. Reduction of 3-(4,5-dimethylthiazol-2-yl)-2,5-diphenol tetrazolium bromide (MTT) was assayed to calculate the number of cells which had migrated (35). MTT $(5 \mathrm{mg} / \mathrm{ml})$ was added to each well of a $96-$ well plate $(10 \mu \mathrm{l} /$ well in $200 \mu \mathrm{l}$ of complete medium $)$ and incubated at $37^{\circ} \mathrm{C}$ overnight. After incubation, the medium was aspirated and the MTT crystals dissolved by addition of $100 \mu \mathrm{l}$ of acidisopropanol. The plate was read within $2 \mathrm{~h}$ at wavelength $540 \mathrm{~nm}$ with a microtitre plate ELISA reader.

Statistical analysis. Results are expressed as mean \pm SEM. Statistical comparisons were made by using analysis of variance with subsequent application of Student's $t$ test, as appropriate.

\section{Results}

Platelet MP induce a time- and dose-dependent increase in the adhesiveness of HUVEC, U-937 cells, and monocytes. The adhesion of unstimulated U-937 cells to platelet MP-stimulated HUVEC increased in a time-dependent manner (Table I, $A$ ). Similarly, MP-stimulated U-937 and monocytes adhered to unstimulated HUVEC (Table I, $C$ and $E$ ). HUVEC and U-937 cells failed to adhere significantly to each other in the absence of pretreating either cell type with platelet MP. However, we observed that $\sim 40 \pm 18 \%$ of unstimulated monocytes adhere to unstimulated HUVEC, which is in agreement with previous reports (36). The kinetics of the alteration in cellular adhesion was dependent on whether HUVEC, U-937 cells, or monocytes were stimulated with platelet MP. When HUVEC were stimulated, the maximal increase in adhesion was observed after $5 \mathrm{~h}$ of exposure to platelet MP (Table I, $A$ ). AA isolated from the platelet MP mimicked the kinetics and magnitude of this response (Table I, $B$ ). When U-937 cells were stimulated with platelet MP, adhesion to HUVEC increased steadily at 1 , 5 , and $24 \mathrm{~h}$ after stimulation (Table I, $C$ ). Again, platelet MP AA mimicked this response (Table I, D). Similarly, when monocytes were stimulated with either MP or MP AA, we observed similar results as for U-937 cells (Table I, $E$ and $F$ ). A

Table I. Time Course Analysis of the Increase in Adhesion of HUVEC, U-937 cells, and Monocytes when Stimulated with $M P(30 \mu \mathrm{g} / \mathrm{ml})$ or $M P A A(30 \mu M)$

\begin{tabular}{cllllcc}
\hline Time (h) & \multicolumn{1}{c}{ A } & \multicolumn{1}{c}{ B } & \multicolumn{1}{c}{ C } & \multicolumn{1}{c}{ D } & \multicolumn{1}{c}{ E } & \multicolumn{1}{c}{ F } \\
\hline 1 & $34 \pm 8$ & $18 \pm 3$ & $30 \pm 9$ & $10 \pm 3$ & $36 \pm 6$ & $46 \pm 21$ \\
5 & $81 \pm 16$ & $63 \pm 13$ & $48 \pm 7$ & $33 \pm 9$ & $68 \pm 16$ & $76 \pm 25$ \\
24 & $41 \pm 13$ & $14 \pm 5$ & $62 \pm 18$ & $75 \pm 21$ & $121 \pm 37$ & $99 \pm 42$
\end{tabular}

The increase in MP- or MP AA-stimulated HUVEC adhesion to unstimulated U-937 cells is represented in columns $A$ and $B$, respectively. Columns $C$ and $D$ represent the increase in U-937 adhesion to unstimulated HUVEC after stimulation with MP or MP AA, respectively. Columns $E$ and $F$ represent the increase in monocyte adhesion to unstimulated HUVEC after stimulation with MP or MP AA, respectively. Values are reported as mean percentage increase \pm SEM of five experiments. 
Table II. A Dose-dependent Increase in Adhesion Evoked by MP or MP $A A$

\begin{tabular}{cccccccc}
\hline MP $(\mu \mathrm{g} / \mathrm{ml})$ & A & B & C & MP AA $(\mu \mathrm{M})$ & D & E & F \\
\hline 0 & $2 \pm 1$ & $7 \pm 3$ & $37 \pm 19$ & 0 & $3 \pm 1$ & $8 \pm 5$ & $42 \pm 17$ \\
3 & $23 \pm 1$ & $16 \pm 4$ & $46 \pm 14$ & 3 & $15 \pm 3$ & $10 \pm 6$ & $56 \pm 15$ \\
10 & $46 \pm 4$ & $33 \pm 9$ & $63 \pm 11$ & 10 & $33 \pm 14$ & $23 \pm 11$ & $70 \pm 11$ \\
30 & $62 \pm 2$ & $50 \pm 10$ & $98 \pm 34$ & 30 & $46 \pm 14$ & $42 \pm 15$ & $125 \pm 37$ \\
100 & $80 \pm 4$ & $63 \pm 7$ & $159 \pm 29$ & 100 & $55 \pm 29$ & $55 \pm 18$ & $188 \pm 25$
\end{tabular}

Columns $A$ and $D$ represent MP- and MP AA-induced increases in HUVEC adhesion to unstimulated U-937 cells, respectively. Columns $B$ and $E$ represent MP- and MP AA-induced U-937 adhesion to unstimulated HUVEC, respectively. Columns $C$ and $F$ represent MP- and MP AA-induced monocyte adhesion to unstimulated HUVEC, respectively. Values are reported as the mean percentage increases in adhesion \pm SEM of four experiments.

dose-dependent increase in adhesion of HUVEC, U-937 cells, and monocytes was also observed after stimulation with increasing concentrations of MP (Table II, $A, B$, and $C$ ). MP AA induced a similar dose-dependent increase in cell adhesiveness
(Table II, $D, E$, and $F$ ). Roughly $1 \mu \mathrm{g} / \mathrm{ml}$ MP protein corresponds to $2 \mu \mathrm{M}$ MP AA.

Platelet MP induce upregulation of HUVEC, U-937 cell, and monocyte surface antigens. Using flow cytometry, we sought to determine whether the augmentation of U-937 cell and monocyte binding to HUVEC was associated with differences in cell surface antigen expression. We found that HUVEC express a basal level of ICAM-1 under resting conditions. This is in agreement with previous reports by other investigators (37). However, ICAM-1 expression increased further upon MP stimulation. Increased ICAM-1 expression was only observed after $5 \mathrm{~h}$ of incubation with platelet MP and declined to basal expression by $24 \mathrm{~h}$ (Fig. $1 A$ ). We did not observe an increase in vascular cell adhesion molecule-1, P-, or E-selectin expression in the activated HUVEC (data not shown).

MP stimulation of U-937 cells increased CD11a and CD11b, but not CD11c (Fig. 2, $A, B$, and $C$ ). However, the kinetics differed from those of MP stimulation of ICAM-1 in HUVEC. Thus, both integrins increased significantly after $1 \mathrm{~h}$ of MP stimulation. Whereas $\mathrm{CD} 11 \mathrm{~b}$ reached equilibrium after $1 \mathrm{~h}$, the expression of CD11a continued to increase over $24 \mathrm{~h}$.

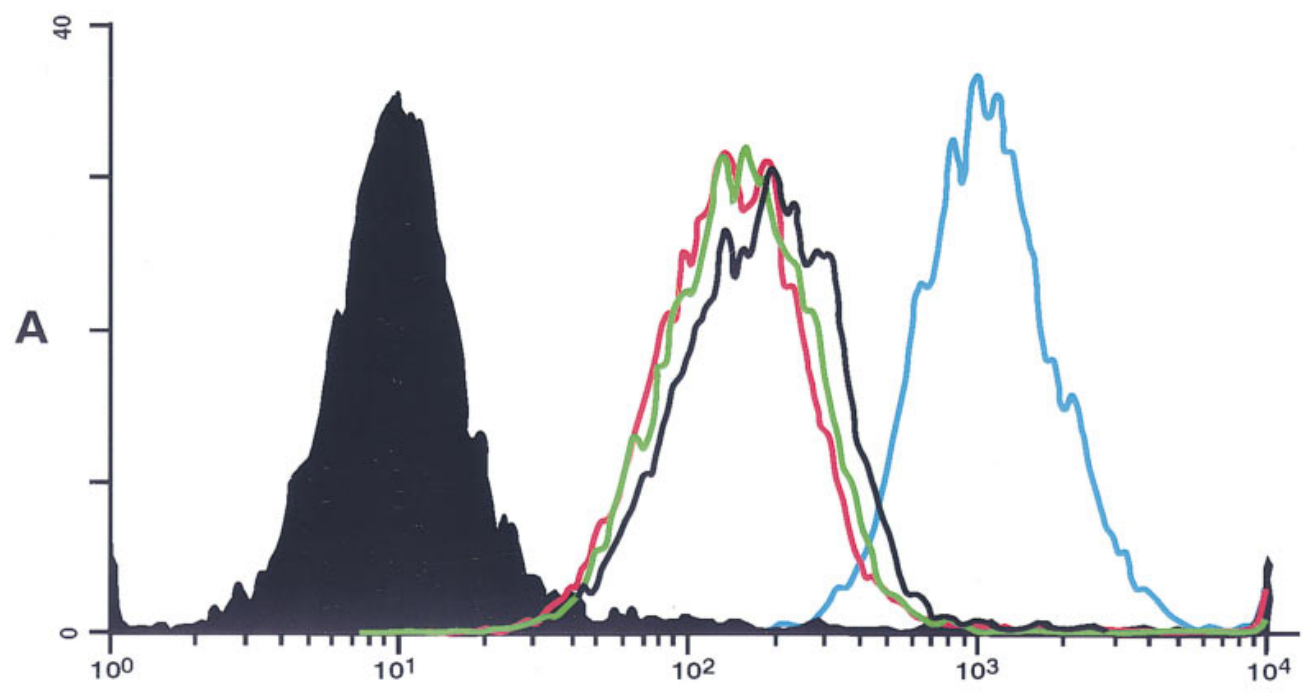

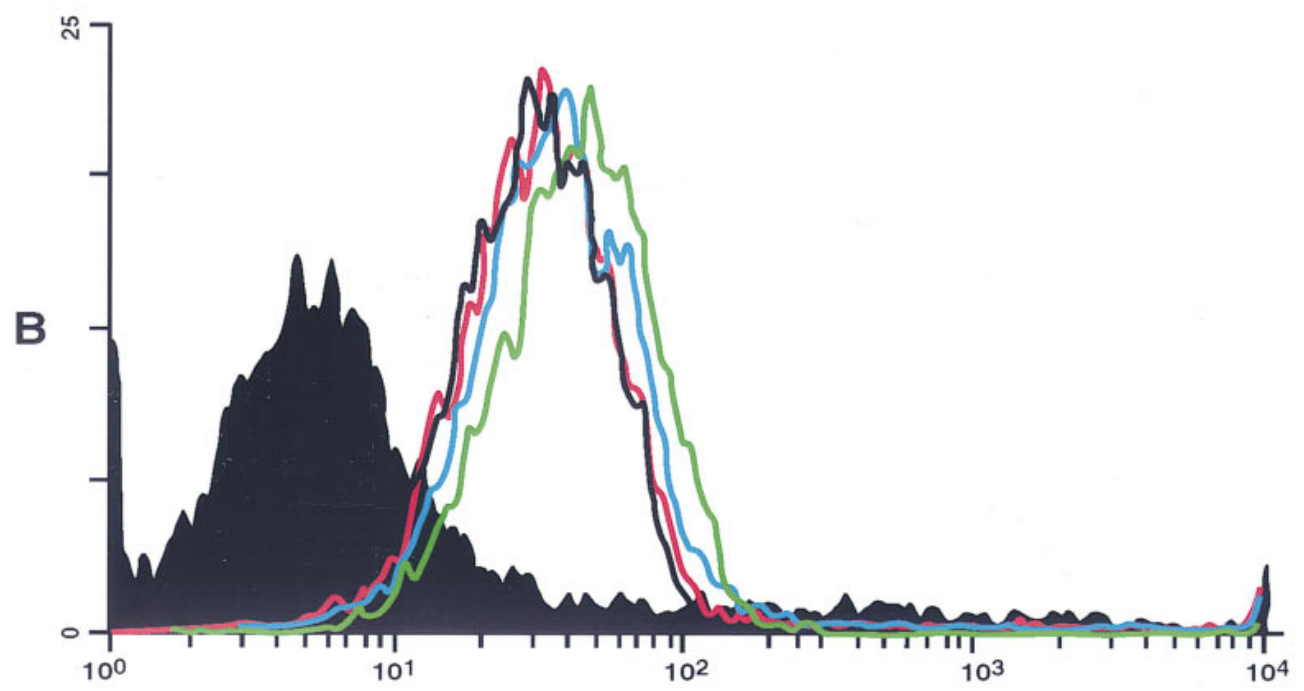

Green Fluorescence
Figure 1. Flow cytometry of HUVEC ICAM-1 expression. HUVEC were stimulated with MP $(30 \mu \mathrm{g} / \mathrm{ml})$ in the absence $(A)$ or in the presence of GF $109203 X(5 \mu \mathrm{M} ; B)$. The filled histogram represents the negative control. Unstimulated HUVEC or HUVEC stimulated with MP for 1, 5, or $24 \mathrm{~h}$ are represented as red, black, blue and green lines, respectively. Flow cytometry was performed as outlined in Methods. The trace is representative of three experiments. 

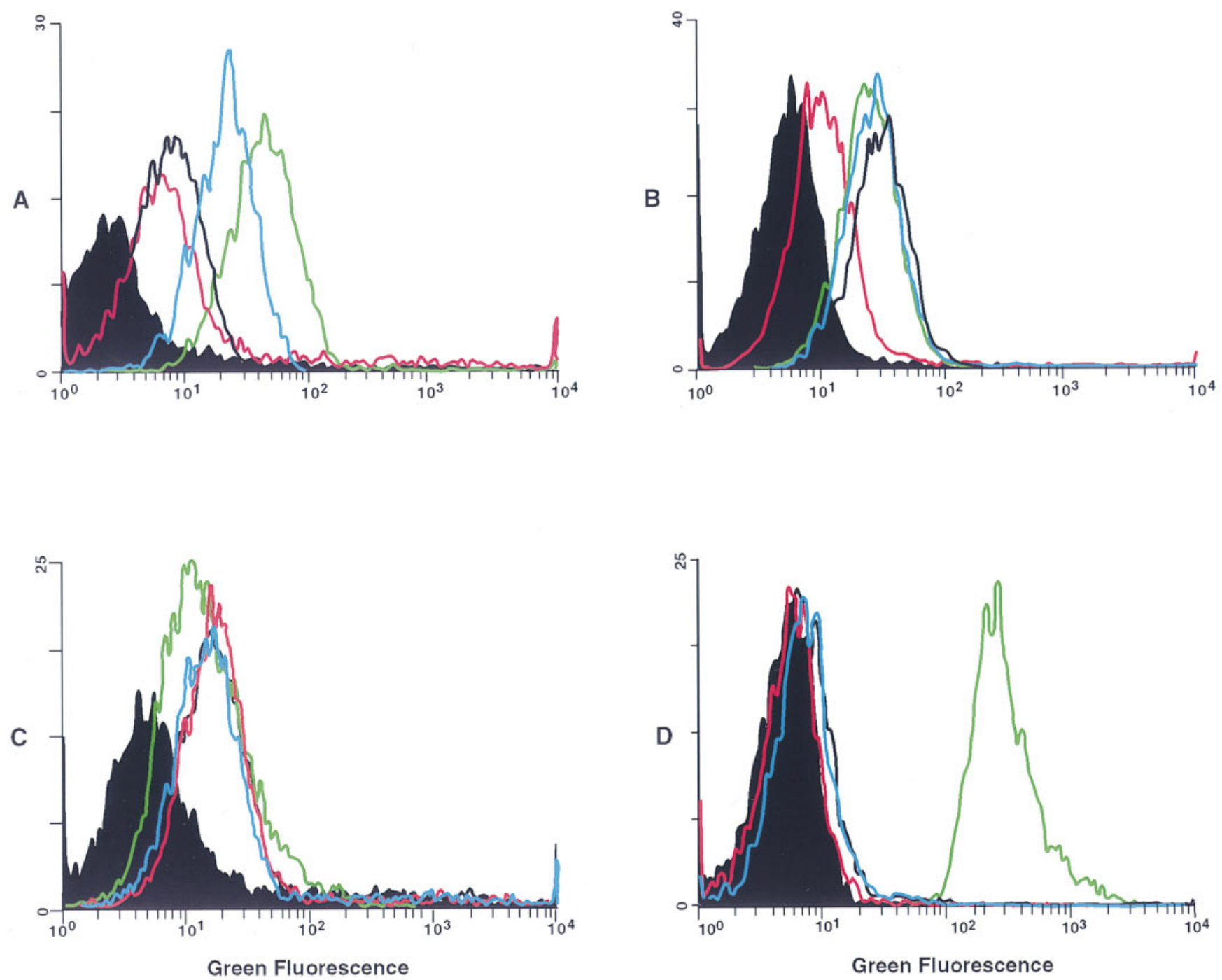

Figure 2. Flow cytometry of U-937 cell CD11a $(A), \mathrm{CD} 11 \mathrm{~b}(B), \mathrm{CD} 11 \mathrm{c}(C)$, and CD14 $(D)$ expression. U-937 cells were stimulated with MP $(30$ $\mu \mathrm{g} / \mathrm{ml})$. The filled histogram represents the negative control. Unstimulated U-937 or U-937 stimulated with MP for 1, 5, or $24 \mathrm{~h}$ are represented as red, black, blue and green lines, respectively. Flow cytometry was performed as described in Methods. The traces are representative of four experiments.

Interestingly, we also observed an increase in CD14 expression, although this was delayed (Fig. 2 D). We did not observe an increase in either very late antigen-1 or ICAM-1 expression (data not shown). Similar results were obtained with human monocytes (data not shown). Again, MP AA mimicked the effects of intact MP. Thus, we observed a similar increase in HUVEC ICAM-1, U-937 cell, and monocyte CD11a, CD11b, and CD14 expression when cells were stimulated with MP AA (data not shown). Indomethacin, present in all experiments described, failed to inhibit the expression of any of the antigens described, indicating that AA, per se, rather than one of its metabolites, was responsible for the observed increase in antigen upregulation in HUVEC, U-937 cell, or monocytes, when each was stimulated with MP AA.

Because we observed similar kinetics in adhesion and antigen expression when either monocytes or U-937 cells were stimulated with MP or MP AA, we used U-937 cells as a model for monocytes in further experiments. U-937 cells exhibit many characteristics of monocytes, including complement and Fc receptors, lysozyme production, and chemotactic responsiveness to $N$-formylmethionyl-leucyl-phenylalanine $(38,39)$.

Platelet MP induce U-937 chemotaxis. The addition of MP or MP AA to the bottom well of a chemotaxis chamber resulted in mean 10- and 6-fold increases in U-937 chemotaxis, respectively, as compared with vehicle control. The optimal MP concentration for U-937 chemotaxis was $30 \mu \mathrm{g} / \mathrm{ml}$ MP protein and $30 \mu \mathrm{M}$ MP AA (Fig. 3).

$M P$-induced adhesion, antigen expression, and chemotaxis is $P K C$ dependent. We investigated the role of $\mathrm{PKC}$ in MPinduced increases in HUVEC, U-937, and monocyte adhesion. PKC inhibition with GF 109203X (40) reduced the adhesion of MP-stimulated HUVEC to U-937 by $87 \pm 1 \%(P<0.003)$ (Fig. $4 A$ ). Similarly, the inhibitor reduced the adhesion of MP-stimulated U-937 and monocytes to resting HUVEC by $67 \pm 4 \%$

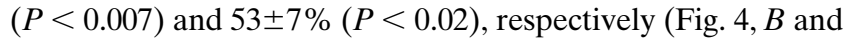
$C)$. By contrast, pretreatment with a PKA inhibitor, H89, 


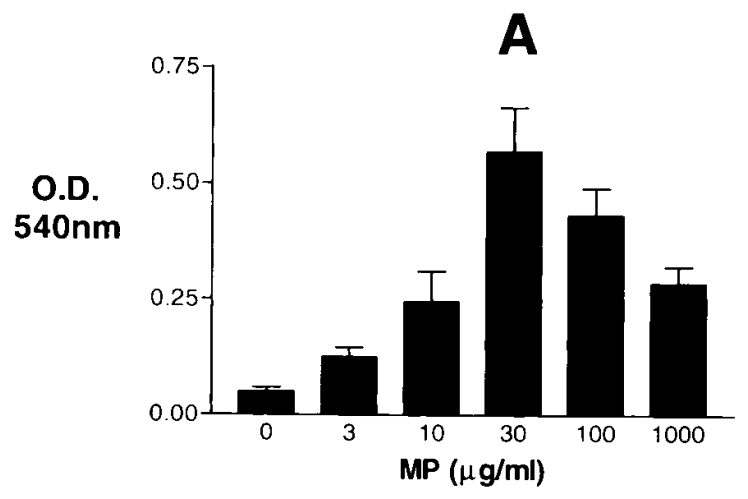

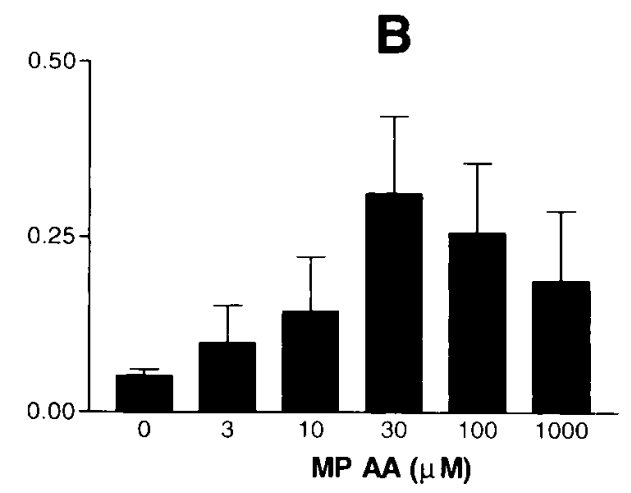

Figure 3. $\mathrm{MP}(A)$ and MP AA $(B)$ dose dependently increase U-937 chemotaxis. U-937 cells $\left(2 \times 10^{5}\right)$ were added to the upper wells of a chemotaxis chamber, and increasing levels of MP protein or MP AA were added to the lower chamber. In both experiments, cells were allowed to migrate for $24 \mathrm{~h}$, and the plate was read at $540 \mathrm{~nm}$. Values are expressed as mean \pm SEM of five experiments. failed to modulate adhesion of either activated HUVEC, U-937 cells, or monocytes. Both actinomycin D and cycloheximide significantly reduced $\operatorname{HUVEC}(P<0.002$ and $P<0.003$, respectively), U-937 ( $P<0.005$ and $P<0.003$, respectively), and monocyte $(P<0.020$ and $P<0.020$, respectively) adhesion (Fig. 4). Similar results were observed when cells were incubated with MP AA (data not shown). This result is somewhat surprising for monocytes and U-937 cells, as new synthesis of $\beta_{2}$ integrins is not usually required for stimulated adhesion of either cell type. The principle mechanisms involved are inside-out signaling of constitutively expressed integrins (41). However, we did not observe a reduction in the intensity of expression of either CD11a or CD11b by flow cytometry in the presence of either actinomycin D or cycloheximide when both cell types were stimulated with either MP or MP AA (data not shown). Thus, it may be possible that these inhibitors are acting on different signaling pathways that are independent of and unrelated to $\beta_{2}$ integrins.

The role of PKC activation in ICAM-1 upregulation has been described previously (42). PKC activation also appears to be critical for MP-induced upregulation of HUVEC ICAM-1 (Fig. 1 B). GF 109203X failed to modulate U-937 cell and monocyte surface antigen expression of CD11a, CD11b, or CD14 (data not shown).

Similarly, PKC has previously been shown to play a role in chemotaxis (43). We addressed the involvement of MP-induced chemotaxis both by pharmacological inhibition and downregu- lation of the enzyme. GF $109203 \mathrm{X}$ reduced cell migration by $90 \pm 2 \%(P<0.003)$, whereas H89 was without effect (Fig. $5 A)$. U-937 cells were pretreated under conditions $(100 \mathrm{nM}$ for $48 \mathrm{~h}$ ) that completely downregulate phorbol ester-responsive PKC isozymes (44), as confirmed by Western blot analysis (data not shown). MP-induced chemotaxis was reduced by $76 \pm 5 \%(P<0.003)$ when U-937 cells were treated in this manner (Fig. 5 B). Similar results were observed when U-937 cells were stimulated with MP AA in the presence of GF 109203X or PMA (data not shown).

Functional importance of antigens mediating adhesion. Anti-CD18, anti-CD11a, and anti-CD11b inhibited U-937 cell adhesion in three cell combinations studied (Fig. 6). AntiCD18 reduced the adhesion of resting U-937 cells to MP-stimulated HUVEC by $40 \pm 3 \%(P<0.03)$, whereas the same antibody reduced the adhesion of MP-stimulated U-937 cells to resting and MP-stimulated HUVEC by $35 \pm 5 \%(P<0.001)$ and $42 \pm 2 \%(P<0.013)$, respectively. Anti-CD11a reduced the adhesion of resting U-937 cells to MP-stimulated HUVEC by $25 \pm 3 \%(P<0.02)$ and MP-stimulated U-937 cells to resting and MP-stimulated HUVEC by $35 \pm 2 \%(P<0.002)$ and $55 \pm 6 \%(P<0.011)$, respectively. Anti-CD11b was also found to inhibit adhesion of resting U-937 cells to MP-activated HUVEC by $34 \pm 3 \%(P<0.030)$ and MP-stimulated U-937 to resting and MP-stimulated HUVEC by $30 \pm 1 \%(P<0.002)$ and $60 \pm 6 \%(P<0.006)$, respectively. Anti-ICAM-1 reduced the adhesion of unstimulated U-937 cells to MP-stimulated HU-
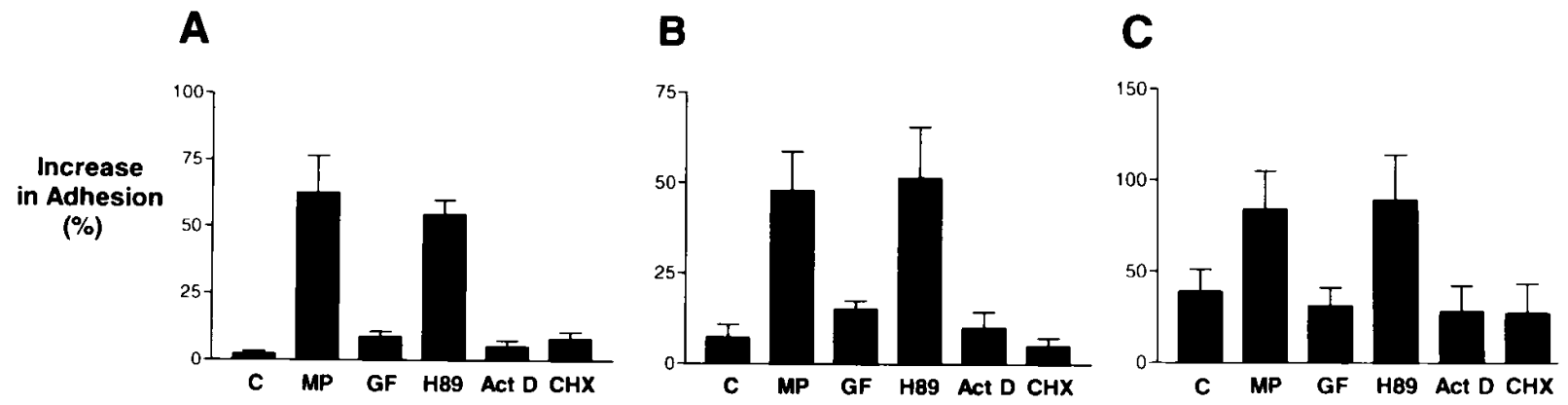

Figure 4. Effect of inhibitors on MP-induced increases in $\operatorname{HUVEC}(A), \mathrm{U}-937(B)$, and monocyte $(C)$ adhesion. Cells were incubated with MP $(30 \mu \mathrm{g} / \mathrm{ml})$ for $5 \mathrm{~h}$ in the presence or absence of GF 109203X $(G F ; 5 \mu \mathrm{M}), \mathrm{H} 89(10 \mu \mathrm{M})$, Actinomycin D $($ Act $D ; 12 \mu \mathrm{M})$, and Cycloheximide $(C H X ; 5 \mu \mathrm{g} / \mathrm{ml})$. The data are the mean \pm SEM of four separate experiments. 

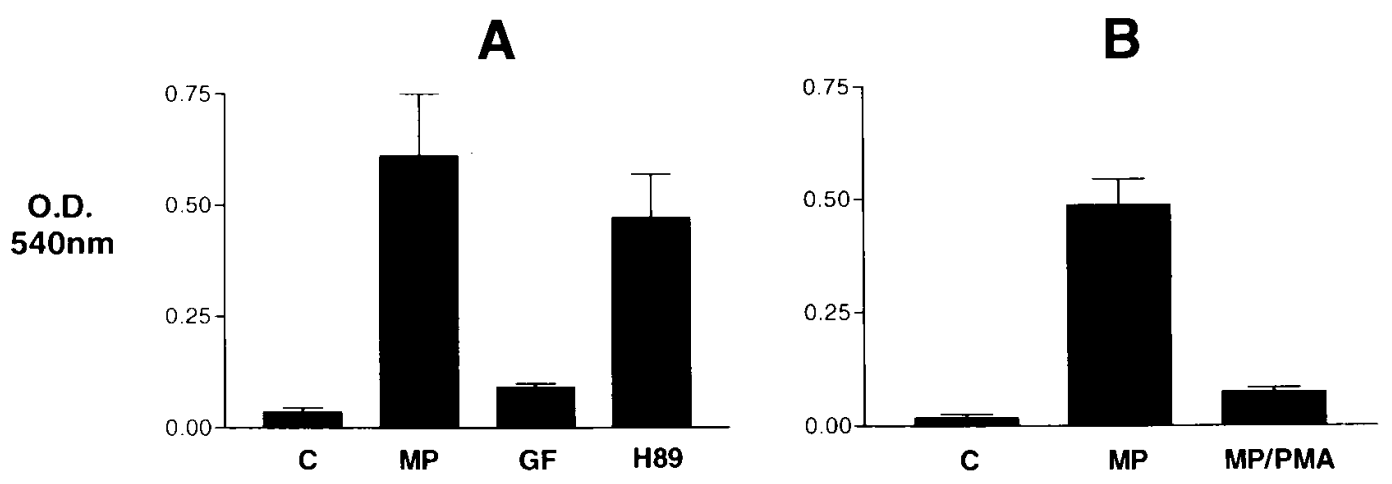

Figure 5. Inhibition or downregulation of PKC inhibits U-937 chemotaxis. $A$ represents inhibition of MP-induced chemotaxis by inhibition of U-937 PKC. U-937 cells were or were not incubated with GF $109203 X$ $(G F ; 5 \mu \mathrm{M})$ or H89 (10 $\mu \mathrm{M})$ for $1 \mathrm{~h}$ before their addition to the chemotaxis chamber. $B$ represents inhibition of MP-

induced chemotaxis by downregulation of U-937 PKC. U-937 cells were incubated with $100 \mathrm{nM}$ PMA for $48 \mathrm{~h}$ before their addition to the chemotaxis chamber. In both experiments, cells migrated for $24 \mathrm{~h}$ and the plate was read at $540 \mathrm{~nm}$. The data are the mean \pm SEM of four experiments.

VEC by $60 \pm 8 \%(P<0.001)$, and MP-stimulated U-937 cells to resting HUVEC by $41 \pm 3 \%(P<0.001)$. However, antiICAM-1 did not significantly reduce adhesion when activated HUVEC were added to activated U-937 (13 $\pm 3 \%, P<0.411$; Fig. 6). Anti- $\beta_{3}$ was ineffective in blocking MP-induced HUVEC, or U-937 cell adhesion (Fig. 6), thereby ruling out the possibility that the MP themselves may potentially act as a bridging or "cross-linking" mechanism for cell-cell adhesion. Anti-CD14 did not influence cell-cell adhesion, despite the upregulation, albeit delayed, of this antigen when U-937 cells were stimulated with MP (data not shown).

\section{Discussion}

Adhesion of monocytes to endothelium is an early event in vascular inflammatory syndromes (45) and, together with subsequent endothelial transmigration, is a feature of developing atherosclerosis (46). Whereas the sequential role of selectins and integrins in mediating this process has been characterized in some detail $(47,48)$, the likely modulating effects of fluid dynamics (27) and local vascular architecture (49) are under current investigation (50). MP are shed from many cells that undergo activation, including platelets (2), endothelial cells (8), and monocytes (3). Although MP are known to contain proteins of recognized biological activity (51), it has been un- clear whether they are of functional importance in vivo. However, recent evidence indicates that MP not only circulate in inflammatory syndromes in humans (52), but may influence tissue function via transcellular donation of bioactive lipids (9). The likelihood that circulating MP might accumulate in the flow vortices that develop at sites in the vasculature prone to development of atherosclerosis (53), prompted us to address the possibility that they might influence cellular interactions of relevance to atherogenesis. In the present study, we report that MP, shed from activated platelets, both enhance the adhesiveness of endothelial, monocytic, and monocytoid cells for each other and promote chemotaxis of monocytoid cells. These effects, however, are recapitulated by AA isolated from the platelet MP and appear dependent upon activation of PKC. Whereas the effects of platelet MP on platelet activation require pretreatment with (s)PLA 2 (9), this was untrue of their effects on adhesive interactions and chemotaxis.

Coincubation of U-937 cells with HUVEC results in minimal adhesive interactions between the two cell types, unlike blood-borne monocytes that do not require activation to adhere to HUVEC, as previously described $(36,37)$. However, exposure of all three cell types to platelet-derived MP results in a dramatic increase in their ability to adhere to each other. The kinetics of this reaction differ, dependent on whether it is the monocyte or endothelial cell that is stimulated with MP. In

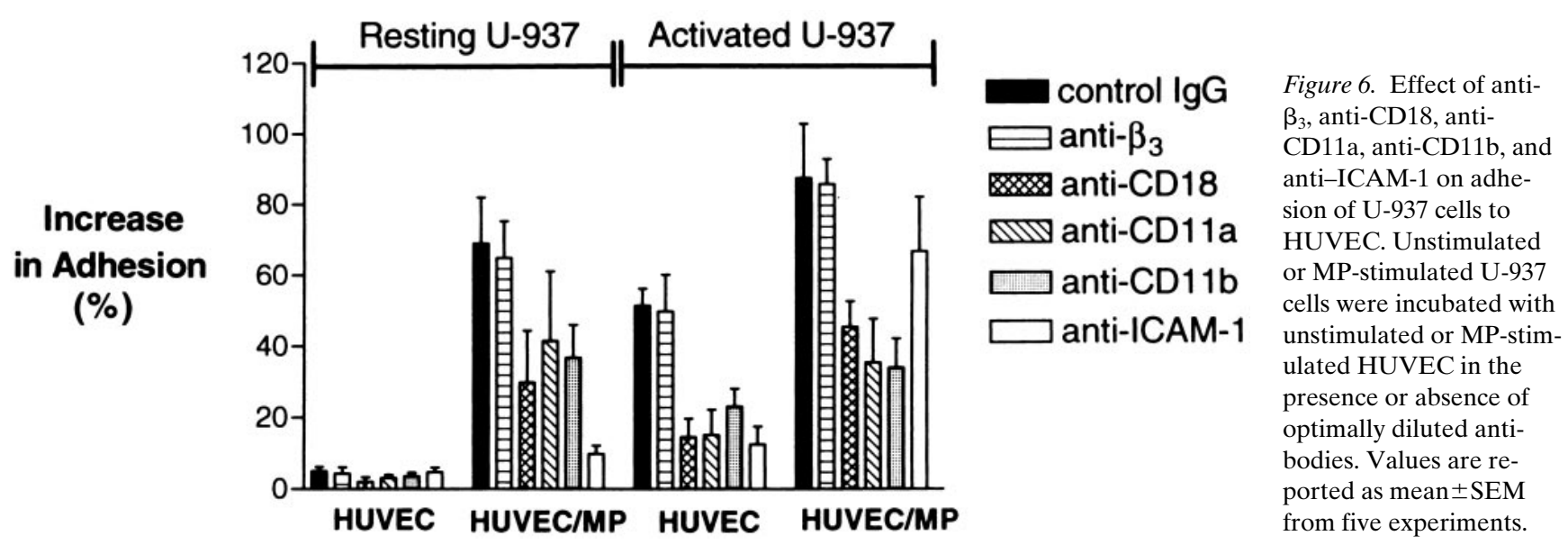


each case, the effects of MP stimulation are recapitulated by AA isolated from the MP, and the magnitude of the responses observed are comparable to those elicited by authentic AA. We have previously described the distribution of AA associated with the platelet pellet and released in MP (9). No evidence for fragmented or modified variants of AA was found by GC/MS analysis of the HPLC fraction. Our assumption is that AA itself, rather than a prostanoid, mediates these effects as indomethacin was present in the medium throughout these experiments. However, we do not exclude a role for other lipids present in the fatty acid fraction isolated from the MP, which may also induce similar effects (48).

We have obtained evidence for the functional importance of antigens expressed by HUVEC, U-937 cells, and monocytes in mediating these interactions. Thus, platelet MP evoke expression of HUVEC ICAM-1 with a time course compatible with the increase in adhesiveness of these cells for unactivated U-937 cells. Similarly, the time course of MP evoked upregulation of U-937 cell and monocyte expression of CD11a, CD11b, and CD14 corresponds to the increment in adhesiveness of both cell types for unstimulated HUVEC.

It has been demonstrated previously that CD14 contributes to the adherence of monocytes to endothelial cells by activating CD11b/CD18 and modulating its affinity for its ligand ICAM-1 (54). Maximum adhesion occurred under conditions where induction of CD14 is observed. However, whereas antibodies that block the function of CD11a and CD11b markedly inhibit adhesive interactions between U-937 cells and HUVEC, anti-CD14 fails to prevent this interaction. This raises the possibility that initial adhesive events are dependent upon CD11a/ICAM-1. However, upregulation of CD14 activates CD11b/CD18, increasing the potential importance of CD11b/ ICAM-1 interactions (54). Antibodies directed against $\beta_{2}$ integrins block the adhesion of unstimulated U-937 to MP-stimulated HUVEC and MP-stimulated U-937 cells to both unstimulated and MP-stimulated HUVEC. Whereas the low levels of ICAM-1 expressed on unstimulated HUVEC will support adhesion via interaction with monocyte CD11 integrins $(55,56)$, they may bind other ligands expressed in HUVEC $(57,58)$. Indeed, anti-CD11a had only a minor effect $(25 \pm 3 \%)$ suppressing adhesion of resting U-937 cells to activated HUVEC. Others have demonstrated that anti-CD11a is ineffective in blocking monocyte adhesion to cytokine-stimulated endothelial cells (59).

Blockade of ICAM-1 was effective in preventing adhesion of activated HUVEC to resting or activated U-937 cells, but was ineffective when both cell types were activated by platelet MP. This accords with previous descriptions. For example, Mantavani et al. observed that monocyte adhesion to unstimulated endothelial cells was suppressed in the presence of antiCD18 but was only moderately reduced in IL-1-treated endothelial cells (45). It is unlikely that very late antigen-1 or vascular cell adhesion molecule-1 play a role in these events; neither is expressed constitutively by HUVEC and they were not induced by pretreatment with platelet MP. Thus, blockade of both $\beta_{2}$ integrins and ICAM- 1 is necessary for marked inhibition of adhesive interactions. Whereas both CD11a/CD18 and/or CD11b/CD18 may mediate CD18-dependent interactions, these integrins can interact with other HUVEC ligands when ICAM-1 is blocked (60).

We have previously shown that platelet MP can activate platelets via PKC (9). Using both PKC downregulation and a pharmacological inhibitor, we now implicate this enzyme in the mechanism of platelet MP-induced adhesive interactions between endothelial cells, U-937 cells, and monocytes. Furthermore, PKC has previously been identified as of importance in mediating lymphocyte interactions with the endothelium and in the induction of ICAM-1 gene expression (61). GF 109203X prevents MP-dependent upregulation of ICAM-1 in HUVEC, and both GF 109203X and PMA-dependent downregulation of $\mathrm{PKC}$ prevent U-937 chemotaxis induced by platelet MP or MP-derived AA.

In summary, platelet-derived MP activate endothelial, monocyte, and monocytoid cells. This results in increased adherence between HUVEC and both U-937 cells and monocytes. Platelet MP also increase U-937 cell chemotaxis. The effects of the MP may be accounted for by their content of unmetabolized AA and involve activation of PKC. Accumulation of platelet-derived MP in flow vortices at sites of vascular constriction or bifrucation may contribute to early steps in atherogenesis via transcellular delivery of this bioactive lipid.

\section{Acknowledgments}

The authors thank Lucia Languino (Yale University, New Haven, Connecticut) for helpful discussions and critical review of the manuscript. We are grateful for the technical assistance of Jeffrey S. Faust (Wistar Institute, Philadelphia, PA).

This work was supported by a grant from the National Institutes of Health (HL4500; Bethesda, MD). G.A. FitzGerald is the Robinette Foundation Professor of Cardiovascular Medicine.

\section{References}

1. Sims, P.J., E.M. Faioni, T. Wiedmer, and S.J. Shattil. 1988. Complement proteins C5b-9 cause release of membrane vesicles from the platelet surface that are enriched in the membrane receptor for coagulation factor Va and express prothrombinase activity. J. Biol. Chem. 263:18205-18212.

2. Sims, P.J., T. Wiedmer, C.T. Esmon, H.J. Weiss, and S.J. Shattil. 1989. Assembly of the platelet prothrombinase complex is linked to vesiculation of the platelet plasma membrane. J. Biol. Chem. 264:17049-17057.

3. Satta, N., F. Toti, O. Feugeas, A. Bohbot, J. Dachary-Prigent, V. Eschwege, H. Hedman, and J.H. Freyssinet. 1994. Monocyte vesiculation is a possible mechanism for dissemination of membrane-associated procoagulant activities and adhesion molecules after stimulation by lipopolysaccharide. $J$. Immunol. 153:3245-3255.

4. Molino, M., D.F. Bainton, J.A. Hoxie, S.R. Coughlin, and L.F. Brass. 1997. Thrombin receptors on human platelets. Initial localization and subsequent redistribution during platelet activation. J. Biol. Chem. 272:6011-6017.

5. Satta, N., J.M. Freyssinet, and F. Toti. 1997. The significance of human monocyte thrombomodulin during membrane vesiculation and after stimulation by lipopolysaccharide. Br. J. Haematol. 96:534-542.

6. Tans, G., J. Rosing, M.C. Thomassen, M.J. Heeb, R.F. Zwaal, and J.H. Griffin. 1991. Comparison of anticoagulant and procoagulant activities of stimulated platelets and platelet-derived microparticles Blood. 77:2641-2648.

7. Iwamoto, S., T. Kawasaki, J. Kambayashi, H. Ariyoshi, and M. Monden. 1996. Platelet microparticles: a carrier of platelet-activating factor? Biochem. Biophys. Res. Commun. 218:940-944.

8. Leeuwenberg, J.F., E.F. Smeets, J.J. Neefjies, M.A. Shaffer, T. Cinek, T.M. Jeunhomme, T.J. Ahern, and W.A. Buurman. 1992. E-selectin and intracellular adhesion molecule-1 are released by activated human endothelial cells in vitro. Immunology. 77:543-549.

9. Barry, O.P., D. Praticò, J.A. Lawson, and G.A. FitzGerald. 1997. Transcellular activation of platelets and endothelial cells by bioactive lipids in platelet microparticles. J. Clin. Invest. 99:2118-2127.

10. Wilentz, J.R., T.A. Sanborn, C.C. Haudenschild, C.R. Valeri, T.J. Ryan, and D.P. Faxon. 1987. Platelet accumulation in experimental angioplasty: time course and relation to vascular injury. Circulation. 75:636-642.

11. Numano, F., Y. Kishi, K. Simokado, F. Numano, and M. Yagima. 1990. Antiplatelet therapy for atherosclerotic disorders. Ann. N.Y. Acad. Sci. 598: 356-367.

12. Kaplan, D.R., F.C. Chao, C.D. Stiles, N.H. Antoniades, and C.D. Scher. 1979. Platelet alpha granules contain a growth factor for fibroblasts. Blood. 53: 1043-1052. 
13. Claesoon-Welsh, L. 1994. Platelet-derived growth factor receptor signals. J. Biol. Chem. 269:32023-32026.

14. Schwartz, L., M.G. Bourassa, J. Lespérance, H.E. Aldridge, F. Kazim, V.A. Salvatori, M. Henderson, R. Bonan, and P.R. David. 1988. Aspirin and dipyridamole in the prevention of restenosis after percutaneous transluminal coronary angioplasty. N. Engl. J. Med. 318:1714-1719.

15. Seeruys, P.W., W. Rutsch, G.R. Heyndricks, N. Danchin, E.G. Mast, W. Wijns, B.J. Rensing, J. Vos, and J. Stibbe. 1991. Prevention of restenosis after percutaneous transluminal coronary angioplasty with thromboxane $\mathrm{A}_{2}$-receptor blockade. A randomized, double-blind, placebo-controlled trial. Coronary Artery Restenosis Prevention on Repeated Thromboxane-Antagonism Study (CARPORT). Circulation. 84:1568-1580.

16. van de Werf, F. 1997. Clinical trials with glycoprotein IIb/IIIa receptor antagonists in acute coronary syndromes. Thromb. Haemostasis. 78:210-213.

17. Willerson, J.T., J.M. McNatt, F.J. Clubb, N. Nicholson, M.P. Herman, J.J. Ferguson, and P. Zoldhelyi. 1997. Xemilofibran, an oral GPIIb/IIIa receptor antagonist is enhanced by aspirin in inhibiting neointimal proliferation following percutaneous coronary angioplasty. Circulation. 96:930a (Abstr.)

18. Topol, E.J., R.M. Califf, H.F. Weisman, S.G. Ellis, J.E. Tcheng, S. Worley, R. Ivanhoe, B.S. George, D. Fintel, H. Weston et al. 1994. Randomized trial of coronary interaction with antibodies against platelet $\mathrm{GpIIb} / \mathrm{III}$ a integrin for reduction of clinical restenosis: results at six months. The EPIC investigation. Lancet. 343:1434-1435.

19. Ross, R. 1985. Platelets, platelet-derived growth factor, growth control, and their interactions with the vascular wall. J. Cardiovasc. Pharmacol. (Suppl. 7) 3:S186-S190.

20. Wissler, R.W. 1991. Update on the pathogenesis of atherosclerosis. Am. J. Med. 91:35-95.

21. Cookson, F.B. 1971. The origin of foam cells in atherosclerosis. Br. J. Exp. Pathol. 52:62-69.

22. Gerrity, R.G., and H.K. Naito. 1980. Ultrastructural identification of monocyte-derived foam cells in fatty streak lesions. Artery. 8:208-214.

23. Boudoulas, H. 1994. Factors determining and prevention of atherosclerotic plaque rupture. Postgrad. Med. J. 70:1:S43-S45.

24. Reilly, I.A., J.B. Doran, B. Smith, and G.A. FitzGerald. 1986. Increased thromboxane biosynthesis in a human model of platelet activation: biochemical and functional consequences of selective inhibition of thromboxane synthase. Circulation. 73:1300-1309.

25. Nomura, S., M. Suzuki, K. Katsura, G.L. Xie, Y. Miyazaki, T. Miyake, H. Kido, T. Kagawa, and S. Fukahara. 1995. Platelet-derived microparticles may influence the development of atherosclerosis in diabetes mellitus. Atherosclerosis. 116:235-240.

26. Kelton, J.G., T.E. Warkentin, C.P.M. Hayward, W.G. Murphy, and J.C. Moore. Calpain activity in patients with thrombotic thrombocytopenic purpura is associated with platelet microparticles. Blood. 80:2246-2251.

27. Davies, P.F., and S.C. Tripathi. 1993. Mechanical stress mechanisms and the cell. An endothelial paradigm. Circ. Res. 72:239-245.

28. Goyert, S.M., E. Ferrero, W.J. Rettig, A.K. Yeramandra, F. Obata, and M.M. Le Beau. 1988. The CD14 monocyte differentiation antigen maps to a region encoding growth factors and receptors. Science. 239:497-500.

29. FitzGerald, G.A., J.A. Oates, J. Hawiger, R.L. Maas, L.J. Roberts, and A.R. Brash. 1983. Endogenous synthesis of prostacyclin and thromboxane and platelet function during chronic aspirin administration in man. J. Clin. Invest. 71:676-688.

30. Bligh, E.G., and W.J. Dyer. 1959. A rapid method of total lipid extraction and purification. Can. J. Biochem. Physiol. 37:911-917.

31. Jaffe, E.A., R.L. Nachman, C.G. Becker, and C.R. Minick. 1973. Culture of human endothelial cells derived from umbilical veins. Identification by morphological and immunological criteria. J. Clin. Invest. 52:2745-2756.

32. Boyum, A. 1968. Isolation of mononuclear cells and granulocytes from human blood. Isolation of mononuclear cells by one centrifugation, and of granulocytes by combining centrifugation and sedimentation at $1 \mathrm{~g}$. Scand. J. Clin. Lab. Invest. 97:77-89.

33. Koski, I.R., D.G. Poplack, and R.M. Blaese. 1976. A nonspecific esterase stain for the identification of monocytes and macrophages. In In Vitro Methods in Cell-mediated and Tumor Immunity. B.R. Bloom and J.R. David, editors. Academic Press, New York. 377-386.

34. Gamble, J.R., and M.A. Vadas. 1988. A new assay for the measurement of the attachment of neutrophils and other cell types to endothelial cells. $J$. Immunol. Methods. 109:175-184.

35. Yufang, S., B.S. Kornovski, R. Savani, and E.A. Turley. 1993. A rapid, multiwell colometric assay for chemotaxis. J. Immunol. Methods. 164:149-154.

36. Carlos, T.M., A. Dobrina, R. Ross, and J.A. Harlan. 1990. Multiple receptors on human monocytes are involved in adhesion to cultured human endothelial cells. J. Leukocyte Biol. 48:451-456.

37. Cavender, D.E., D. Edelbaum, and L. Welkovich. 1991. Effects of inflammatory cytokines and phorbol esters on the adhesion of U-937 cells, a hu- man monocyte-like cell line, to endothelial cell monolayers and extracellular matrix proteins. J. Leukocyte Biol. 49:556-578.

38. Sudstrom, C., and K. Nilsson. 1976. Establishment and characterization of a human histiocytic lymphoma cell line (U-937). Int. J. Cancer. 17:565-577.

39. Fischer, D.G., M.C. Pike, H.S. Koren, and R. Snyderman. 1980. Chemotactically responsive and nonresponsive forms of a continuous human monocytic cell line. J. Immunol. 125:463-465.

40. Toullec, D., P. Pianetti, H. Coste, P. Bellevergue, T. Grand-Perret, M. Ajakane, V. Baudet, P. Boissin, E. Boursier, F. Loriolle, L. Duhamel, D. Charon, and J. Kirilovsky. 1991. The bisindolylmaleimide GF $109203 \mathrm{X}$ is a potent and selective inhibitor of protein kinase C. J. Biol. Chem. 266:15771-15781.

41. Ginsberg, M.H., X. Du, and E.F. Plow. 1992. Inside-out integrin signaling. Curr. Opin. Cell Biol. 4:766-771.

42. Springer, T.A. 1990. Adhesion receptors in the immune system. Nature. 346:425-434.

43. Derman, M.P., A. Toker, J.H. Hartwig, K. Spokes, J.R. Falck, C.S. Chen, L.C. Cantley, and L.G. Cantley. 1997. The lipid products of phosphoinositide 3-kinase increase cell motility through protein kinase C. J. Biol. Chem. 272:6465-6470.

44. Olivier, A.R., and P.J. Parker. 1992. Identification of multiple PKC isoforms in Swiss 3T3 cells: differential down-regulation of phorbol ester. J. Cell Physiol. 152:240-244.

45. Mantovani, A., and E. Dejana. 1989. Cytokines as communication signals between leukocytes and endothelial cells. Immunol. Today. 10:370-375.

46. Issekutz, T.B., A.C. Issekutz, and H.Z. Movat. 1981. The in vivo quantitation and kinetics of monocyte migration into acute inflammatory tissue. Am. J. Pathol. 103:47-55.

47. Bevilacqua, M.P., R.M. Nelson, G. Mannori, and O. Cecconi. 1994. Endothelial-leukocyte adhesion molecules in human disease. Ann. Rev. Med. 45: 361-378.

48. Zimmerman, G.A., T.M. McIntyre, and S.M. Prescott. 1996. Adhesion and signaling in vascular cell-cell interactions. J. Clin. Invest. 98:1699-1702.

49. Davies, P.F., K.A. Barbee, R. Lai, A. Robotewskyi, and M.L. Griem. 1995. Hemodynamics and atherogenesis. Endothelial surface dynamics in flow signal transduction. Proc. Natl. Acad. Sci. USA. 748:86-102.

50. Davies, P.F., K.A. Barbee, M.V. Volin, A. Robotewshyj, J. Chen, L. Joseph, M.L. Griem, M.N. Wernick, E. Jacobs, D.C. Polacek, N. dePaola, and A.I Barakat. 1997. Spatial relationships in early signaling events of flow-mediated endothelial mechanotransduction. Annu. Rev. Physiol. 59:527-549.

51. Nomura, S., Y. Komiyama, T. Miyake, Y. Miyazaki, H. Kido, M. Suzuki, H. Kagawa, M. Yanabu, H. Takahashi, and S. Fukuhara. 1994. Amyloid betaprotein precursor-rich platelet microparticles in thrombotic disease. Thromb. Haemostasis. 72:519-522.

52. Lee, Y.J., W. Jy, L.L. Horstman, J. Janania, Y. Reves, R.E. Kelley, and Y.S. Ahn. 1994. Elevated platelet microparticles in transient ischemic attacks, lacunar infarcts, and multiinfarct dementias. Thromb. Res. 72:295-304.

53. Holme, P.A., U. Orrim, M.J. Hamers, N.O. Solum, F.R. Brosstad, R.M. Barstad, and K.S. Sakariassen. 1997. Shear-induced platelet activation and platelet microparticle formation at blood flow conditions as in arteries with a severe stenosis. Atheroscler. Thromb. Vasc. Biol. 17:646-653.

54. Beekhuizen, H., I. Blokland, and R. vanFurth. 1993. Cross-linking of CD14 molecules on monocytes results in a CD11/CD18- and ICAM-1-dependent adherence to cytokine-stimulated human endothelial cells. J. Immunol. 150:950-959.

55. Pober, J.S., M.A. Gimbrone, L.A. Lapierre, D.L. Mendrick, W. Fiers, R. Rothlein, and T.A. Springer. 1986. Overlapping patterns of activation of human endothelial cells by interleukin 1, tumor necrosis factor, and immune interferon. J. Immunol. 137:1893-1896.

56. Dustin, M.L., and T.A. Springer. 1988. Lymphocyte function-associated antigen-1 (LFA-1) interaction with intercellular adhesion molecule-1 (ICAM-1) is one of at least three mechanisms for lymphocyte adhesion to cultured endothelial cells. J. Biol. Chem. 107:321-331.

57. Diamond, M.S., D.E. Staunton, A.R. de Fougerolles, S.A. Stacker, J. Garcia-Aguilar, M.L. Hibbs, and T.A. Springer. 1990. ICAM-1 (CD54): a counter-receptor for Mac-1 (CD11b/CD18). J. Cell Biol. 111:3129-3139.

58. Lo, S.K., G.A. Van Seventer, S.M. Levin, and S.D. Wright. 1989. Two leukocyte receptors (CD11a/CD18 and CD11b/CD18) mediate transient adhesion to endothelium by binding to different ligands. J. Immunol. 143:3325-3329.

59. Beekhuizen, H., A.J. Corsel-Van Tilburg, I. Blokland, and R. Van Furth. 1991. Characterization of the adherence of human monocytes to cytokine-stimulated human macrovascular endothelial cells. Immunology. 74:661-669.

60. Rice, G.E., J.M. Munro, and M.P. Bevilacqua. 1990. Inducible cell adhesion molecule 110 (INCAM-110) is an endothelial receptor for lymphocytes. A CD11/CD18-independent adhesion mechanism. J. Exp. Med. 171:1369-1374.

61. Renkonen, R. 1990. Activation of protein kinases A and C increases lymphocyte penetration through endothelial monolayers. FEBS Lett. 267:89-92. 